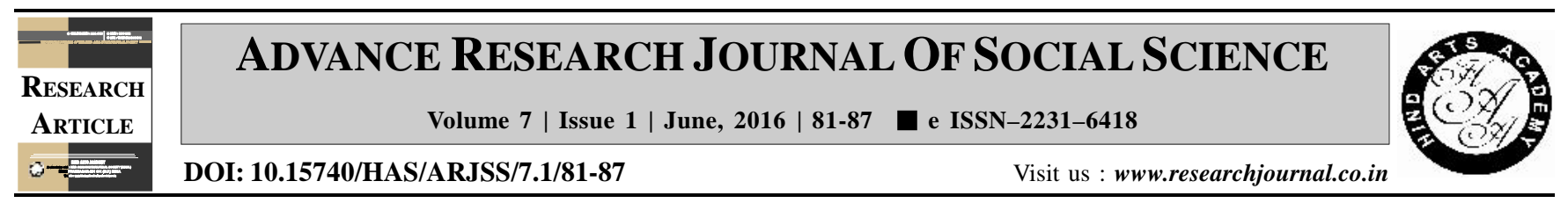

\title{
Practices adopted by rural and urban housewives to combat indoor pollution
}

D. Kaur*, M. Sidhu and S. Bal

Department of Family Resource Management, College of Home Science, Punjab Agricultural University, LUDHIANA(PUNJAB) INDIA

\section{ARTICLE INFO :

$\begin{array}{lll}\text { Received } & : & 28.03 .2016 \\ \text { Revised } & : & 14.04 .2016 \\ \text { Accepted } & : & 15.05 .2016\end{array}$

KEY WORDS :

Air quality, Dust management, Ill effects, Indoor pollution

HOW TO CITE THIS ARTICLE :

Kaur, D., Sidhu, M. and Bal, S. (2016). Practices adopted by rural and urban housewives to combat indoor pollution. Adv. Res. J. Soc. Sci., 7 (1) : 81-87, DOI: 10.15740/HAS/ARJSS/7.1/81-87.

*Author for correspondence

\begin{abstract}
Indoor pollution consists of toxic gases, dust particles, suspended particulate matter (SPM) dust mites, fungus etc. that can harm the inmates' health. Indoor sources of toxic gases or particles can increase indoor pollutant levels much higher than those found outdoors. As there are many sources of indoor pollutants, and because people spend most of their time indoors, indoor exposures can be of high intensity and pose a significant risk to the health of the inmates. About 68.33 per cent homemakers perceived that due to indoor pollution, inmates can have headache, and 67.50 per cent respondents agreed that it can lead to irritation to throat. Minimum response was for Sick Building Syndrome and Tobacco Syndrome each as reported by 36.67 per cent respondents. Maximum number $(81.67 \%)$ of respondents was aware of the fact that one has to install ventilators for improvement of indoor air quality and it was followed by the 65.00 per cent respondents who knew that exhaust fans were also effective. Little more than half $(58.33 \%)$ of respondents had the knowledge that using wire mesh on windows and doors can be very effective to control indoor pollution. Almost half of them $(51.67 \%)$ agreed that they were aware of airing new furniture, rugs, mattresses etc, $(50.00 \%)$ agreed that they were aware of indoor air getting polluted due to new paints or varnishes and these should be aired well. And (46.67\%) agreed that they were aware of airing summer clothes before wearing them. Minimum awareness was reported by the respondents for 'airing out dry cleaned clothes', 'attending leaking taps' and 'not using artificial fragrances' as disclosed by 31.67, 34.17 and 39.17 per cent respondents respectively. It was also revealed in the study that urban respondents had higher awareness on these issues as compared to rural respondents.
\end{abstract}

